\title{
Digital Visual Sensing Design Teaching Using Digital Twins
}

\author{
Lu Lian $(1)$ and Yao Yan \\ School of New Media Arts, Xi'an Polytechnic University, Xi'an 710048, Shaanxi, China \\ Correspondence should be addressed to Lu Lian; 12111852231@stu.wzu.edu.cn
}

Received 3 November 2021; Accepted 23 December 2021; Published 18 January 2022

Academic Editor: Zhihan Lv

Copyright ( $\odot 2022 \mathrm{Lu}$ Lian and Yao Yan. This is an open access article distributed under the Creative Commons Attribution License, which permits unrestricted use, distribution, and reproduction in any medium, provided the original work is properly cited.

\begin{abstract}
Digital twin technology can support teachers in this major to complete monitoring related topics and application research and serve teaching and scientific research through the establishment of automatic monitoring teaching model laboratory and in-depth combination with the current students' skill training needs in this major. This exploration aims to make the visual sensor industry have a steady stream of talents. Promoting the development of visual sensor technology is to promote the development of science and technology. Based on the teaching research of visual sensing design using digital technology, a set of teaching systems of visual sensing design is designed by using the methods of literature research and investigation and analysis. Special topics are set up from the aspects of professional subjects; regarding course content, various sensor principle research courses, visual sensor design courses, experimental courses, and example courses are set up; teaching methods are divided into online and offline synchronous classes; the evaluation method should focus on the distribution, examples, and practice. The results show that traditional classroom teaching is seriously separated from extracurricular learning. Most students are in a state of passive acceptance of knowledge and have few thinking activities. The established teaching system integrates brain and cognition, photoelectric foundation, sensory imaging, visual sensing imaging, visual sensing technology courses, computer technology, virtual experiment courses, and physical experiment courses. It can carry out more than 30 experiments of optical microscopic imaging and X-ray imaging based on the principle of visual sensing. Therefore, the teaching effect and teaching mode of the proposed digital visual sensing teaching system have been greatly improved.
\end{abstract}

\section{Introduction}

In the twenty-first century, people are used to digitization and seek the optimal solution of learning and life through big data. It means that people have unknowingly entered the digital age, such as the music app that judges and recommends users' favorite songs through big data, lists of popular film and television dramas, and online shopping of favorite items. People have experienced great changes brought about by the digital age. Now, everyone cannot live without numbers. Digital twins (DTs) complete the mapping of the physical model in virtual space in the real world. Physical model refers to all kinds of equipment in the real world: human, mechanical arm, numerically controlled machine tool, automatic instrument, and mobile phone. The virtual world can be simply understood as a digital world composed of various intelligent computing devices; through the DTs technology, every device in the real world will have a digital entity in the virtual world, which has exactly the same appearance and internal structure The characteristics of the digital age include intelligence, integration, and parallelism [1]. The traditional teaching mode needs to invest a lot of physical equipment, venues, and personnel. It also has to face the problems of normal loss and accidental damage of physical objects, which cannot reduce the cost. Applying DTs technology to online teaching can break the traditional teaching mode and realize digital teaching.

$\mathrm{Li}$ and Wang (2017) [2] introduced the teaching exploration of sensor technology based on artificial intelligence (AI). Compared with traditional network teaching, sensor intelligent teaching system needs a more complex computer operation mechanism, which is mainly reflected in the following three aspects. (1) Models are established according to the characteristics of different students. (2) Suggestions 
are shared according to existing teaching strategies such as teaching objectives and training programs and combined with data resources. (3) Human-computer interaction is adopted in an intelligent teaching system. Liu et al. (2019) [3] proposed teaching reform and explored the postgraduate course of new sensor principle and application theory. Based on the introduction of theory, the explanation and analysis of application cases were added. For example, target recognition technology based on image acquisition and pattern recognition was introduced into vision sensing technology. The explanation of application cases was convenient for students to master the basic principle, application, and data processing methods of sensors and enriched the theoretical teaching content; the teaching mode adopted multimedia teaching; the assessment method was " $30 \%$ theoretical written test $+30 \%$ experimental practice $+20 \%$ usual results $+20 \%$ report display." Tao et al. (2019) [4] put forward the information-based teaching design before, during, and after class based on "craftsman spirit." With the course of robot vision and sensing technology as an example, it showed the concept of allowing students to integrate into enterprises and participate in scientific research, exhibitions, and other activities, shaping the spirit of workers and craftsmen, and carrying out "one lesson, one lecture." The second class, skill competition, discipline training, science and technology festival, and other activities encourage cooperation, exploration, and excellence. They used the process of preclass guidance, classroom learning research, simulation exercises, and after-class expansion.

This study uses a combination of literature research and investigation and analysis to study the visual perception instructional design of DTs. Pure AI or multimedia teaching is used separately, and there is no combined teaching method. The innovation is that the visual sensing design teaching system is designed to be different from traditional teaching. The establishment of the visual sensor design discipline makes up for the regret that there is no professional visual sensor design course in the major. This system pays more attention to teaching practice, helps reduce the phenomenon that the input and output of education are not proportional, and provides research ideas for other professional settings such as auditory perception design.

\section{Materials and Methods}

2.1. DTs. DTs are the simulation processes that make full use of physical model, sensor update, operation history, and other data; fuse different disciplinarians, physical quantities, scales, and probabilities; and complete the mapping in the virtual space, so as to reflect the whole life cycle process of the corresponding physical equipment. DTs create a virtual model for physical objects in a digital way to simulate their behavior in the real environment. Building a DTs production system integrating the manufacturing process can realize the digitization of the whole process from product design to production planning to manufacturing execution and raise the level of product innovation and manufacturing efficiency and effectiveness to a new level. The DTs body refers to a virtual model completely corresponding and consistent with the physical entities in the real world, which can simulate its behavior and performance in the real environment in real time, also known as the DTs model. It can be said that DTs are technology, process, and method, and DTs body is object, model, and data.

The application of DTs technology to the design of efficient teaching experiments can enable students to be exposed to the current monitoring technology in an all-round way and deeply understand the current situation of the industry. It can train massive scarce talents in the direction of deformation monitoring and improve the social service function of the laboratory. The construction of the DTs world is not only for graphical viewing but also for rapid quantitative statistics and intelligent analysis. In the "DTs," one of the twins is an entity existing in the real world, ranging from parts to factories, simple as screws and complex as the structure of the human body. The other twin only exists in the virtual and digital world, which is a symmetrical mirror image of the real world created by digital technology. It can map various attributes of physical equipment into virtual space to form a digital image that can be disassembled, copied, transferred, modified, deleted, and repeated with the help of design tools, simulation tools, internet of things, virtual reality, and other digital means.

2.2. Digital Technology. Digital technology, as its name implies, is a technology that is based on numbers. From its category, it is a computer technology and the basic application category of modern computer technology. Digital technology flourished after the twentieth century and has been closely related to human development. Its basic principle is to turn nonmeasurable data into measurable data, and then the corresponding data model is established, enabling it to be recognized by a computer. Digital code is restored after operation, processing, storage, and transmission [5]. The principle of digital technology is shown in Figure 1.

2.3. Sensing Technology. The original circuit of the sensor is similar to the principle of digital technology. It converts the measured quantity into a certain physical quantity convenient for application according to a certain law. A sensor includes the sensitive element, conversion element, and measuring circuit [6]. It has four concepts, and one of them is the working principle of the sensor, as shown in Figure 2.

2.4. Visual Sensing Technology. Visual sensing design, as its name implies, is one of a variety of sensing designs. It is a visual processing system based on computer technology. Human perception of external environmental information is generally carried out through sensory organs. Among industry production, $80 \%$ of the information comes from vision. Therefore, vision is the foundation and core in the research field of sensing technology. At present, there are two polarity methods for research on visual sensing technology. And researchers use two completely different methods to study visual perception. The first one is to 


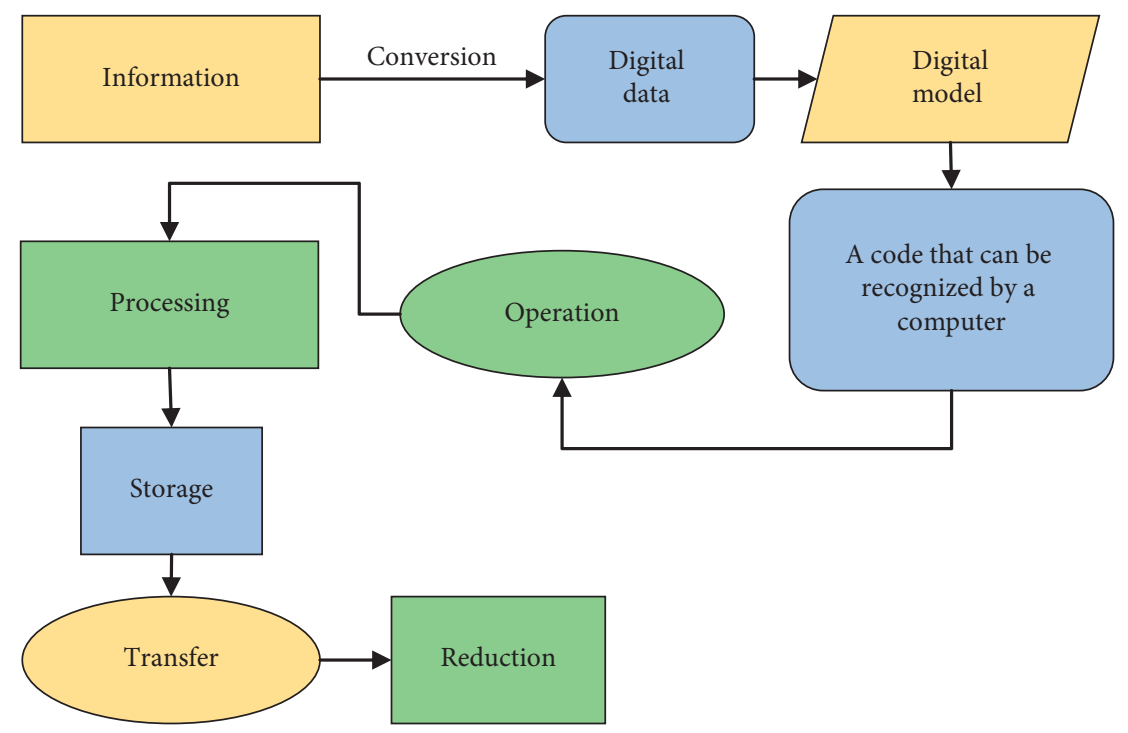

Figure 1: Schematic flow chart of digital technology.

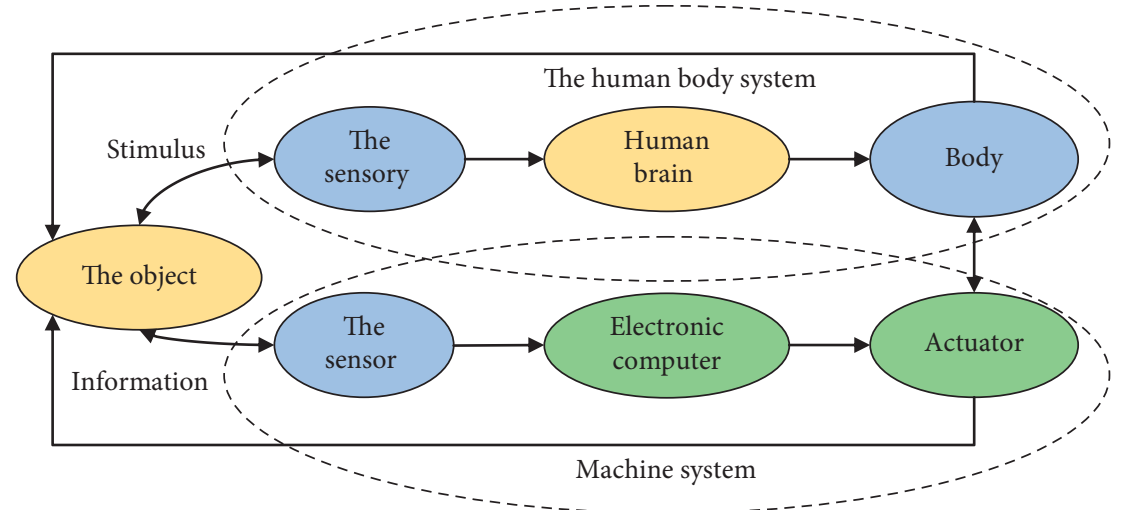

FIgURE 2: Schematic diagram of sensing technology.

establish a model structure to simulate the "biological eye," which is called biological vision. Biological vision is similar to building a single-lens camera eye to imitate the human eye. Caltech has established a silicon biological structure model, including silicon retina and silicon ear. People pay more attention to the biometric system, but with the limitation of low human eye pixel technology, it is hard to break through the pixel work of the human eye. Also, since people are with little knowledge about the working process of sensory organs, so the biometric system has been difficult to break through. Then another method is used more often. It is to acquire an image through an image input device and then analyze and distinguish the image, which is called computer vision or machine vision [7]. Therefore, it does not have the limitations of the above biological system. It is developing steadily and is composed of six parts: sensor, lens, auxiliary light source, image acquisition card, computer, and display. Sensors have two kinds: CCD (charge-coupled device) and CMOS (complementary metal-oxide-semiconductor). CCD is not only superior to CMOS in imaging quality but also has the advantages of linear array CCD and area array CCD.
Linear CCD can capture a one-dimensional image, and area CCD can capture a two-dimensional plane image. Therefore, most industrial sensors are CCD sensors [8]. According to whether the light source is used or not, visual sensing is divided into passive light vision and active light vision [9]. The principle flow chart of visual sensing technology and the structure diagram of the visual sensor are shown in Figures 3 and 4 , respectively.

2.5. Measurement Method. Visual sensing technology aims to obtain depth information through a direct connection, and it is an important development direction of visual sensing technology. It includes volume vision measurement, single-camera measurement, beam adjustment measurement, and so on. The volume vision measurement is based on the principle of stereo parallax, and it uses two or more cameras using the known spatial position relationship. Through the theories of epipolar geometry and parallax principle, the scene image of the same measured object is obtained, and the three-dimensional geometric information 


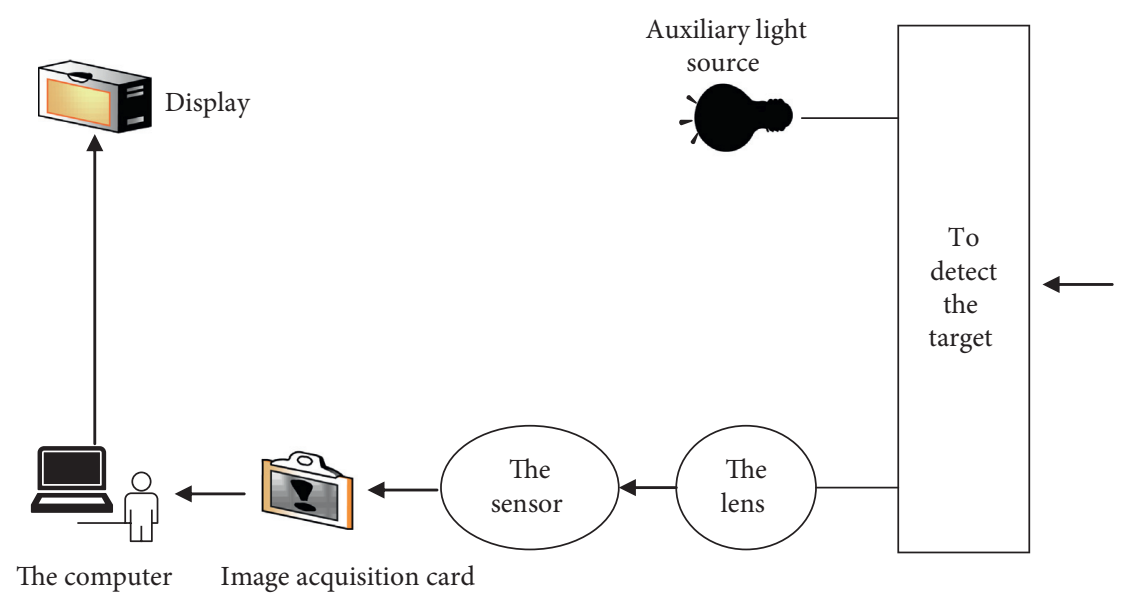

Figure 3: Principle flow chart of visual sensing technology.

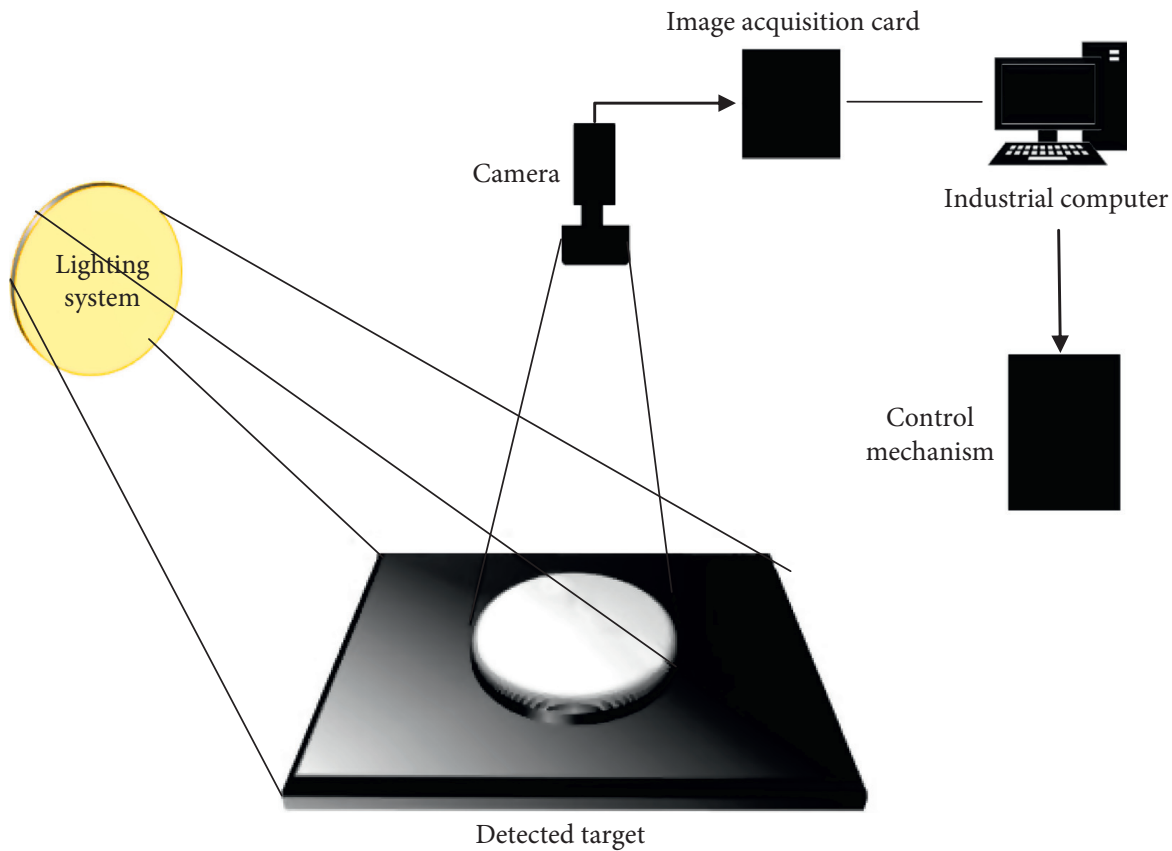

FIGURE 4: Structure diagram of a vision sensor.

of the measured object is solved. Single-camera measurement refers to the use of a single camera to image the measured object. It combines the control point technology to realize the real measurement, which is a method to measure the spatial three-dimensional geometric information of the measured object. People cannot reverse it from a single two-dimensional image through control point technology. Then, an accurate target probe is used, by adding the single image 3D information to the prospective model, to add additional geometric constraints. Consequently, the accurate target probe can measure 3D geometric information of space objects. Beam adjustment measurement is a geometric model that is based on the spatial intersection of imaging beams. It takes the beam adjustment algorithm to optimize it as the core. Multiple measuring points are set at different positions in the measurement space through the camera. Through a high-precision image processing algorithm and automatic image point registration technology, it collects measuring points from different positions and attitudes to obtain the iterative strip for beam adjustment. And then, it obtains the accurate three-dimensional coordinates of the measuring points by using the beam adjustment optimization algorithm. The measurement method is used in the teaching reform and exploration theory of the above new sensor principle and application postgraduate course. The measurement method is the basis and core of visual sensing technology. Without a measurement method, everything cannot continue. The teaching method of measurement method is multimedia teaching. The assessment method adopts the proportion of " $30 \%$ theoretical written test $+30 \%$ experimental practice $+20 \%$ usual results $+20 \%$ report and display." The contents of the new sensor principle and application course are shown in Figure 5. 


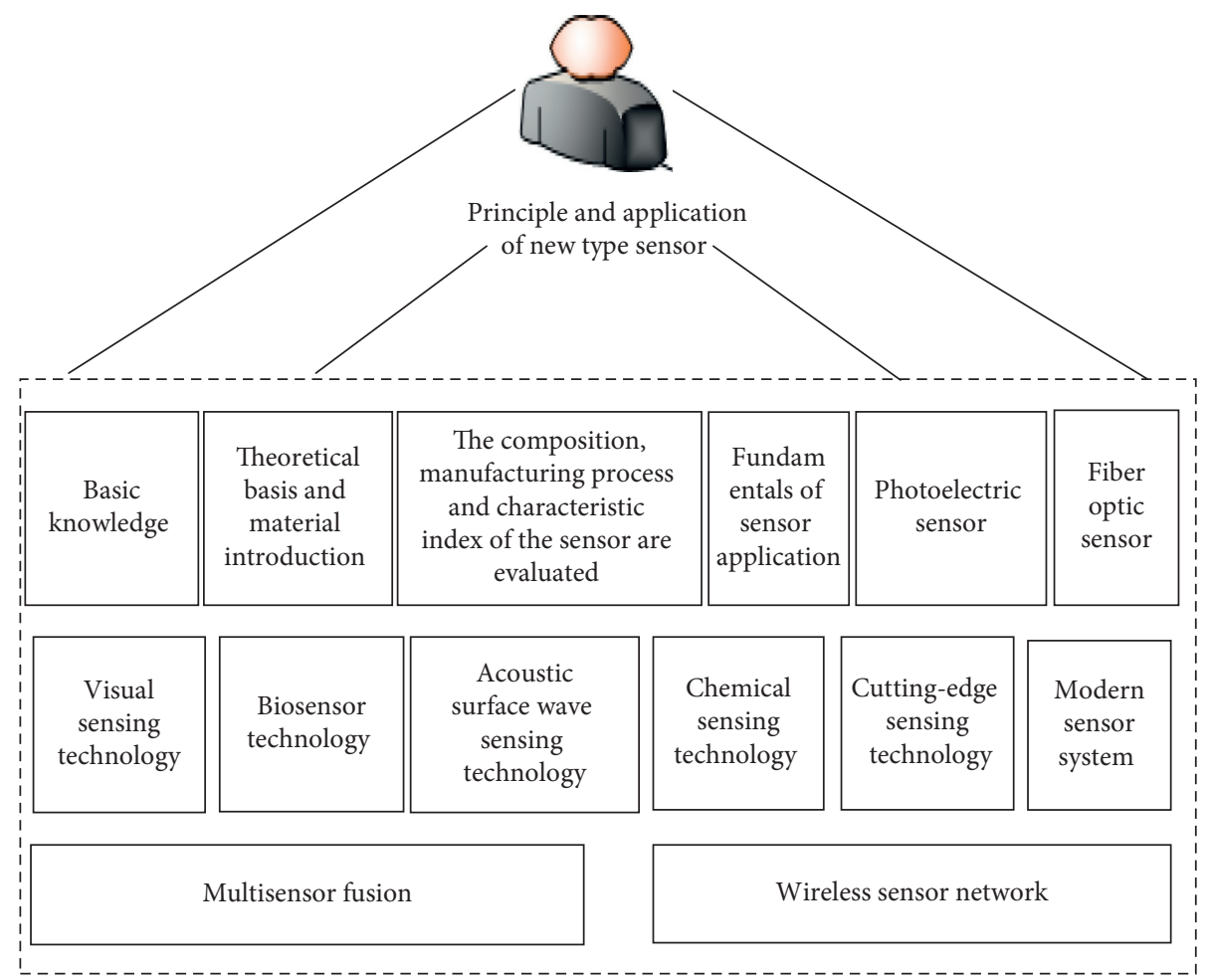

FIgURE 5: Course content diagram of new sensor principle and application.

\section{Methods of Precision Teaching}

Precision teaching is a new teaching method. It was used for targeted education at the beginning of its birth, aiming to obtain relevant data by designing and measuring the teaching process, track students' learning performance, and provide data decision support for teaching. The main measure is fluency, which is composed of "accuracy" and “proficiency speed" of students' corresponding knowledge and skills. The traditional monitoring method of precision teaching is to analyze by manually drawing measurement tables, which is too cumbersome. And the results are often not accurate enough due to the lack of big data and AI in the early stage. However, the development of technology has become mature and used in all aspects of life, such as precision marketing. It can intelligently set the minimum value of reliability and confidence of the data mining algorithm. For students, it can automatically prompt the knowledge points that may not be good in the follow-up. For teachers, it can automatically predict the overall teaching effectiveness of the class and analyze the associated knowledge points.

3.1. A Priori Algorithm. An algorithm based on precise teaching and big data is proposed. Based on the unique digital mining technology in the digital age, it analyzes students' weak subjects to launch courses suitable for students. In the background, teachers can also identify the shortcomings of classes through observation data to adjust learning methods over time.
Basic definition. Definition 1 (support): let $I=\{\mathrm{i} 1, \mathrm{i} 2, \ldots$, $i n$ \} be a set containing $N$ items, transaction $T$ be a set of items, $T \subseteq I$ and $D$ be a set of $T$. Let $A$ be a set of items, transaction $T$ contain $X$, and only $X \subseteq T$, that is, $X$ is contained in $T, X \longrightarrow Y$ is an expression of an association rule, and $X \subset I$, $Y \subset I, X \cap Y=\varnothing$.

$$
\begin{aligned}
\operatorname{Support}(X \longrightarrow Y) & =P(X \cup Y) \\
& =\frac{\{T: X \cup Y \longrightarrow T, T \in D\}}{D \times 100 \%=a} .
\end{aligned}
$$

Definition 2 (confidence). the confidence of association rules $X \longrightarrow Y$ refers to the ratio of the number of transactions containing $X$ and $Y$ to the number of transactions containing only $X$, expressed as follows:

$$
\begin{aligned}
\text { confidence }(X \longrightarrow Y) & =P(X \mid Y \\
& =\frac{\operatorname{support}(X \cup Y)}{\operatorname{support}(X) \times 100 \%} .
\end{aligned}
$$

\section{Results}

4.1. Analysis of Existing Problems. It is found that there are few professional projects on visual sensing design in colleges and universities. And, at present, the teaching content of sensing design is biased towards junior college, for example, bionic intelligent sensing design, robot visual sensing and technology, image sensing technology, and application belong to photoelectric information science and engineering. 
As a result, the curriculum content is more inclined to junior college than visual sensing design. Then, the visual sensing design discipline is needed. Also, some students still do not realize that they are the main body of the learning process, their learning enthusiasm and initiative are not high, and they cannot actively participate in teaching activities. Besides, the limitation of teaching time and insufficient interaction time between teacher and students are still the traditional teaching state of "teachers say and students listen" [10]. The separation between classroom teaching and extracurricular learning is serious. Most students are in a state of passive acceptance of knowledge, and they have few thinking activities. It is difficult to cultivate students' thinking ability and innovative spirit. Students will find theory teaching boring. The course evaluation method is not perfect, and it is difficult to judge students' comprehensive ability. Therefore, it is necessary to improve the traditional teaching methods and assessment methods. The reformed teaching system is described below.

4.2. Reformation of Teaching System. Firstly, in terms of course content, it establishes a major in visual sensing technology. It is minor in computer technology, sensor technology, principle, and application of new sensors. The teaching content should also be continuously improved with the development of the times. It refers to intelligent sensing and detection technology [11], sensor and detection technology [12], and image sensing technology and application [13]. For the established professional courses, it considers the scientific system, the basic framework of visual sensing technology courses, and the relationship between various parts. It integrates brain and cognition, photoelectric foundation, sensory imaging, visual sensing imaging, visual sensing technology course, computer technology, virtual experiment course, physical experiment course, and so on. And it establishes this new professional basic course. The teaching structure and content of the prepared handout are shown in Figure 6.

The first module is the learning of various sensor principles, including pressure and force sensors, position sensors, liquid level sensors, energy consumption sensors, speed sensors, acceleration sensors, radiation sensors, thermal sensors, vibration sensors, humidity sensors, magnetic sensors, gas sensors, vacuum sensors, biosensors, and so on. It introduces the sensing technology, the concept of the sensor, the application, development, significance, principle, and general application scope of the sensor.

The second module is the study of computer technology. In the digital age, all processes are inseparable from numbers and computers. Therefore, computers are a key step to learning visual sensing design well. They mainly explain the basic principles of computers and programming-related knowledge.

The third module is the learning of visual sensors, and it is mainly focusing on the visual sensing imaging of information. For example, in optical microscopic imaging, it introduces the principles of optical Fourier analysis, diffractive optics, and Abbe imaging. And it also introduces the basic principles and technologies of fluorescence microscopic imaging, phase contrast microscopic imaging, polarization microscopic imaging, and electron microscopic imaging. The basic principle and devices of X-ray imaging, the basic principle of CT imaging, and the image reconstruction algorithm of projection are also introduced. Learning of visual sensor introduces the basic principle of nuclear magnetic resonance imaging, the basic principle of nuclear magnetic resonance imaging (MRI), Fouriertransform image reconstruction, and so on. It introduces ultrasonic imaging and medical B-ultrasound imaging. Figures 7 and 8 show optical microscopy and X-ray imaging, respectively [14].

The fourth module is the study of virtual and physical experiments. It directly combines the teaching of the experimental process with the theory. The study of virtual and physical experiments enables students to design virtual animation experiments independently. This enhances students' creative ability, reduces the consumption of experimental equipment, and lays a foundation for students to conduct physics experiments. The teaching of the experiment should be designed and comprehensively applied experiments, and more than 30 experiments based on various visual sensing principles such as optical microscopy and X-ray imaging can be carried out. Therefore, teachers should encourage students to conduct self-designed experiments and 12-hour experimental classes. It is important to simplify the experiment. Figure 9 shows an example of animation when students are doing experiments. It clearly expresses the concentration and earnestness of students in the practical courses of visual perception.

The key point is to verify the compression principle and increase the proportion of design and comprehensive experiments so that students cannot be limited to reading the experimental data only. People should also be able to combine electronic circuit knowledge with computer control technology, collect data on the computer, build a basic automatic test system, enable students to give free play to the space, and improve their hands-on ability and practical ability in the process of free experiment [15].

The fifth module is an example of a visual sensing design system. Firstly, the principle of visual sensing technology and the imaging technology of visual sensing are briefly introduced and reviewed, and it recalls the experimental process through animation. Next, it introduces the application examples of visual sensing design, such as the relevant foundation of the robot, intelligent robot and its software and hardware system, robot vision, and intelligent robot examples [16].

In terms of teaching methods, it is recommended to use offline new media teaching and teacher teaching, as well as online video playback, animation interaction, and other methods to provide learning for students. In the teaching process, teachers should pay more attention to the introduction of teaching content, pictures, animation, and other forms of expression. In normal teaching, the text should be combined with theoretical and experimental teaching content. Students' understanding of knowledge concepts is more vivid and intuitive using new media teaching and 


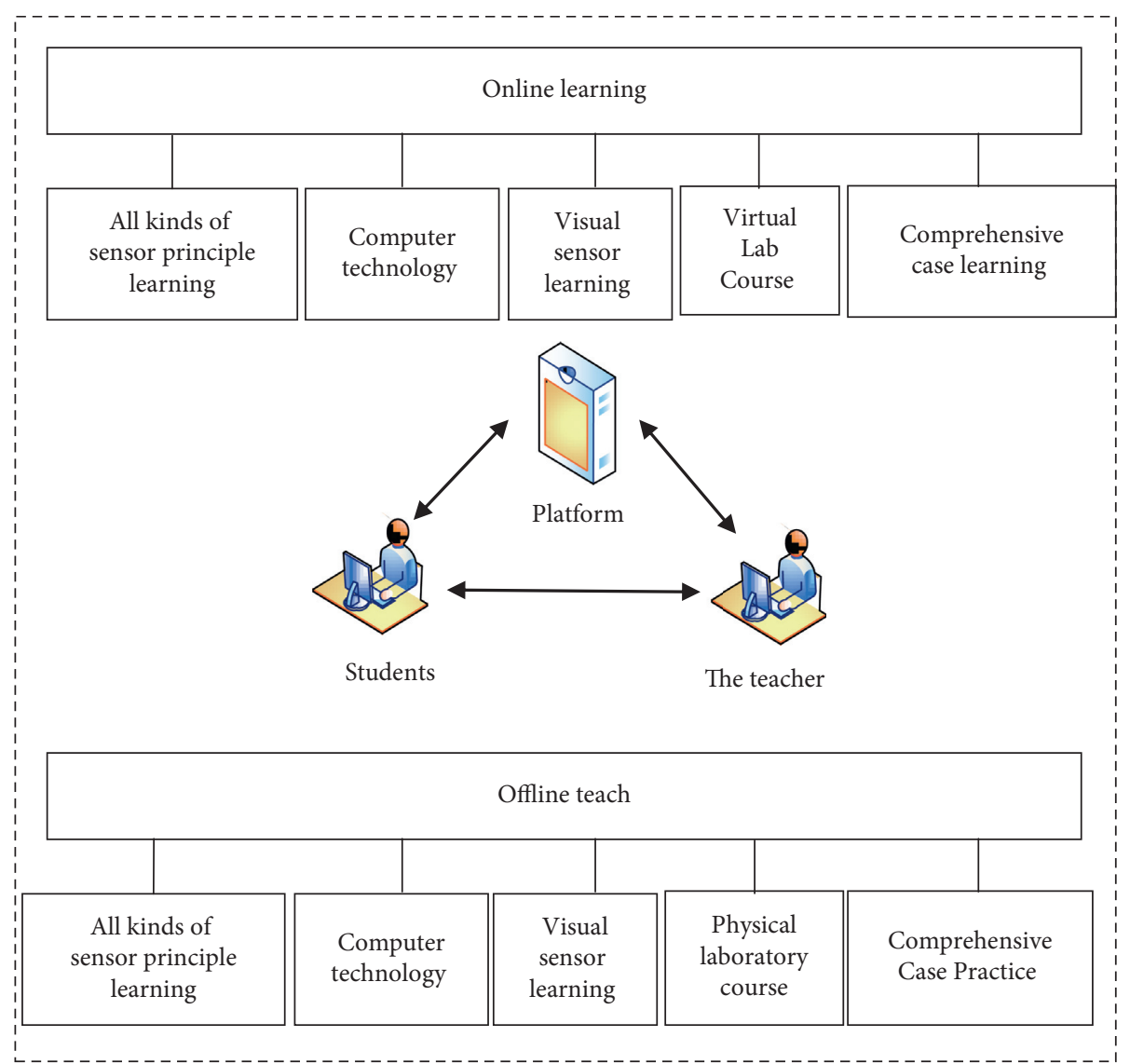

FIgURE 6: Content map of improved visual sensing design course.

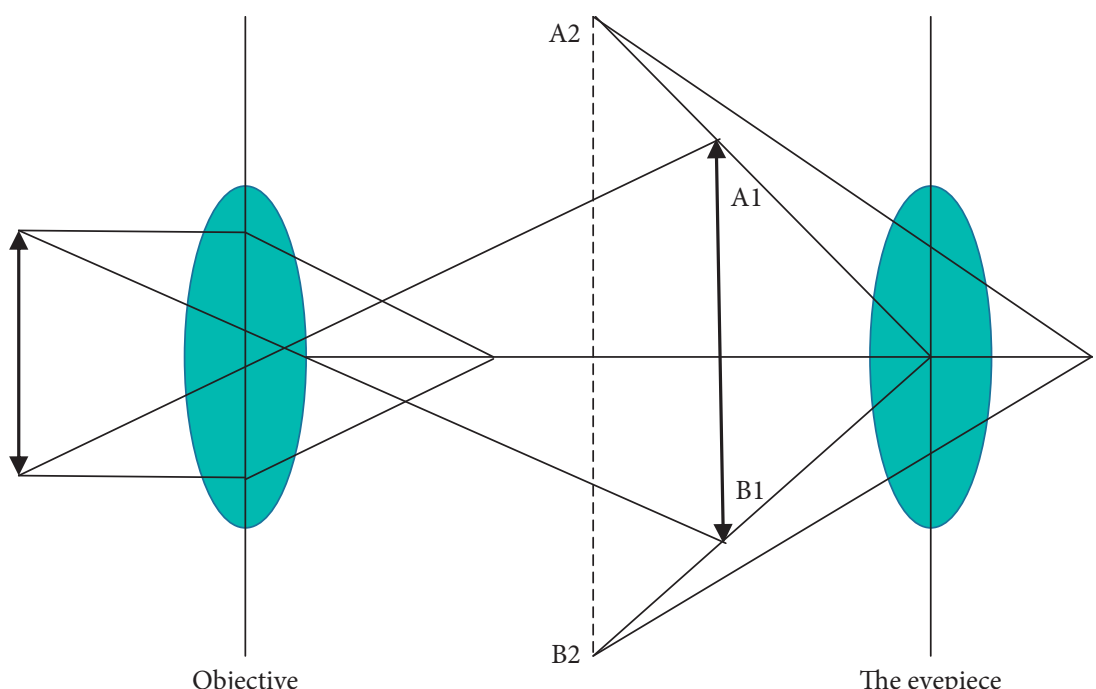

FIgURE 7: Optical microscopy. 


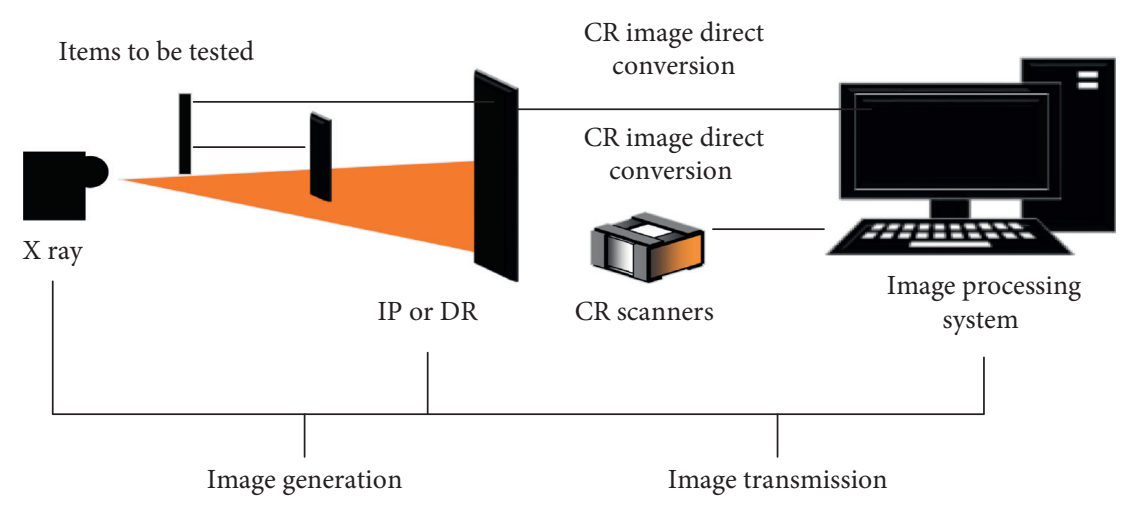

Figure 8: X-ray image.

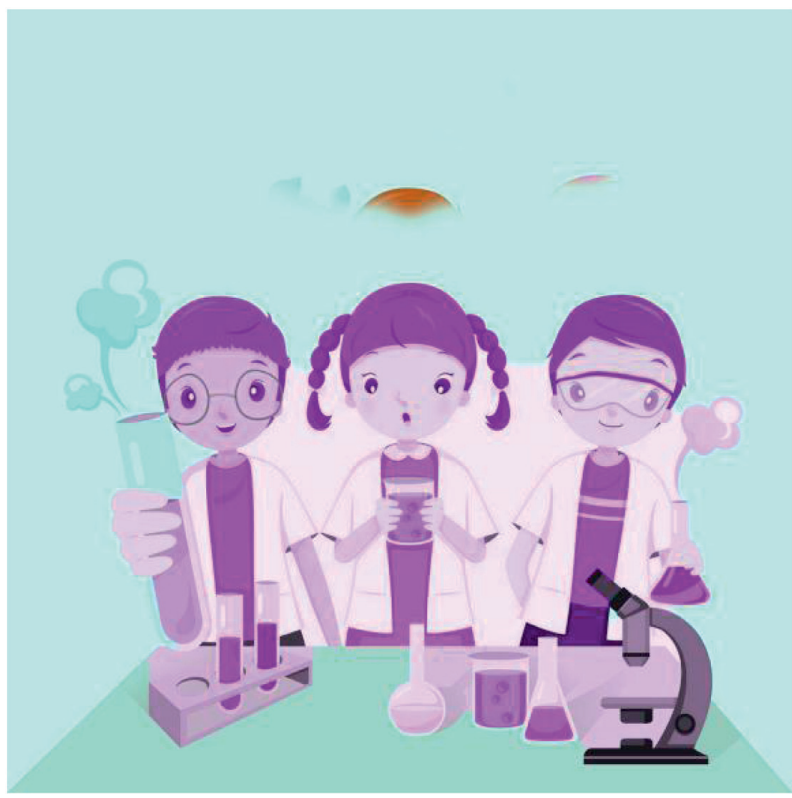

FIGURE 9: Reference relative experimental animation.

animation. The use of new media teaching and animation allows students to understand the structure of the visual sensor and clarify the working principle of the visual sensor and its application examples. It can also improve the learning efficiency of students [17]. Figure 10 is an example of students' interactive learning through online animation. The advanced computer system provides a new research direction for the teaching mode.

4.3. Visual Sensing Design Course. The teaching effect is scored according to a full score of 100 . The proposed precision teaching method is compared with the teaching effect of similar teaching methods in the literature $[18,19]$. The levels of student knowledge, classroom activity, and teacherstudent interaction are compared, as shown in Figure 11.

In Figure 11, the precision teaching model proposed has the highest scores in the three dimensions of student knowledge mastery, classroom activity, and teacher-student interaction, all reaching more than 90 points. Among them, the score of teacher-student interaction is 96 points, indicating that the proposed teaching method based on visual sensor design can greatly increase teacher-student interaction and improve the overall effect of teaching.

\section{Discussion}

New media mainly adopts PowerPoint teaching and animation interaction in this process. Before this, the workload is often tedious and trivial, with huge content and many knowledge points. Students are very tired during class, lack concentration, or cannot recall previous knowledge points. The knowledge points of learning classroom content must be focused, and the process of content teaching must be logical. The important formula derivation process still needs to be combined with the teacher's handwritten presentation so that the students can understand it by themselves. The understanding of knowledge points is deeper than simple formula memorization and straightening out the thinking of the whole class. Meanwhile, the teacher arranges for students 


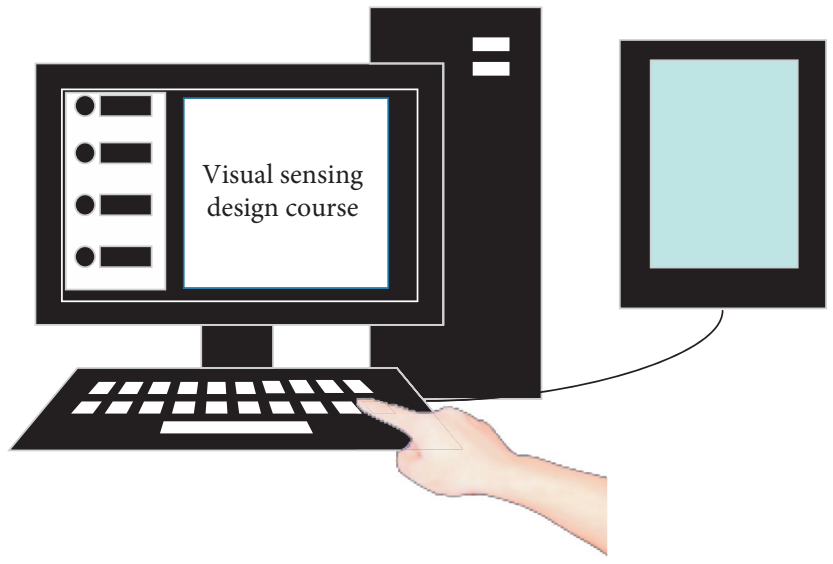

FIgURe 10: Interactive learning example diagram.

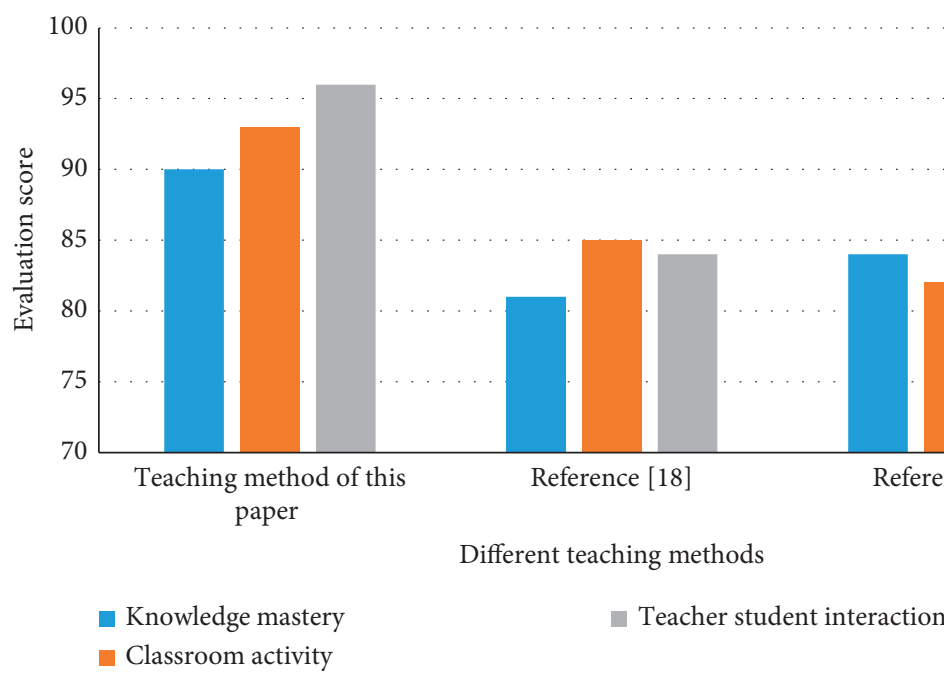

Figure 11: Comparison of different teaching methods.

to study, organize, and analyze some key content. In the first 10 minutes of each class, the teacher asks the students to summarize the learning content of the previous class and briefly introduce the content of this class. This not only can achieve classroom interaction and improve students' enthusiasm but also can set an example and exercise for some people who are eager to work as teachers. As for other students, the teaching process is also an opportunity to consolidate learning [20, 21].

When the intelligent visual sensor is introduced, students are asked to review the content of the previous class and cooperate with the teacher's explanation of the intelligent visual sensor to fully mobilize students' learning enthusiasm and give full play to the role of autonomous learning. Through classroom multimedia theory teaching, key content teaching, and application case analysis, students' theoretical learning level can be improved, and students can actively develop online learning and independent learning and make interactive courseware for an explanation. It can effectively stimulate students' interest and enthusiasm in teaching activities and promote the improvement of students' learning methods. Through the combination of college student training projects and scientific research projects, students are encouraged to combine the research content and interest projects of the sensor major and invited to participate in experimental research and design innovative experiments. This promotes the organic combination of theoretical research and scientific research practice. In the process of teaching practice, the course gradually established a teaching method that combines classroom learning, online learning, experimental learning, and autonomous learning $[22,23]$.

If only changing the course content and teaching methods, teachers will only take temporary solutions not effect a permanent cure. The reform of the teaching effect assessment and evaluation methods should be further explored based on changing the weight ratios of various aspects of the assessment results. The proposed method adjusts the final score composition of the examination evaluation and converts the ratio of the traditional " $70 \%$ written test $+20 \%$ experiment $+10 \%$ usual score" to " $30 \%$ theoretical written test $+30 \%$ experimental practice $+20 \%$ usual score $+15 \%$ 
report display $+5 \%$ practice" ratio to increase the proportion of practice sessions [24-26]. The changed test evaluation standards are more practical. Finally, a demonstration evaluation system is constructed based on basic theoretical knowledge and experimental practical skills, supplemented by a comprehensive evaluation method of classroom student learning efficiency, interaction, and the display and explanation of the final practical results. Basic theoretical knowledge should fully cover knowledge points and comprehensive application capabilities.

The experimental design focuses on the candidates' practical ability, the ability to design experiments in combination with theoretical knowledge, the ability to complete the experimental process, and the ability to analyze the results. The usual assessment results are mainly the usual attendance, the interactive knowledge questions and answers with teachers and students in the classroom, and the completion of homework [27-29]. At the end of term, the display of research results is conducive to the combination of theory and knowledge, focusing on the comprehensive ability of subject investigation, data sorting, thinking and summarizing, report writing, and oral expression. This method can cultivate students' comprehensive quality in asking questions, analyzing problems, and solving problems. Finally, the level of the internship score mainly depends on the candidate's ability to adapt to society [30-32].

\section{Conclusion}

Since entering the digital age, people rely more and more on the use of machines. Nowadays, sensors are the core and foundation of machine manufacturing, and the observation of the world mostly depends on the eyes. Therefore, the teaching and research of visual sensing design are very crucial. A scheme to cultivate the ability of visual sensing design, experiment, innovation, and practice are designed. The system can be adopted by talents in intelligent machines, biological systems, and machine detection, that is, set up special disciplines from the perspective of professional disciplines and set up various sensor principle research courses, computer technology courses, visual sensor design courses, experimental courses, and example courses in the course content. Teaching methods are divided into online and offline synchronous classes. Moreover, an accurate teaching method based on a data mining algorithm is added and applied, which has the effect of checking leaks and filling vacancies. Regarding evaluation methods, the evaluation proportion is " $30 \%$ theoretical written test $+30 \%$ experimental practice $+20 \%$ usual score $+15 \%$ report and display $+5 \%$ practice," focusing more on students' practical operation ability and practical application ability. The disadvantage is that it cannot go deep into everyone's requirements to make everyone learn better through their own learning habits. The learning methods applicable to each student based on this topic will be further explored so as to make the research of this discussion more detailed.

\section{Data Availability}

The experimental data used to support the findings of this study are available from the corresponding author upon request.

\section{Conflicts of Interest}

The authors declare that they have no conflicts of interest regarding this work.

\section{Acknowledgments}

This work was supported by Shaanxi Association of Social Sciences, research on innovative communication of red culture with farmer's painting of Huxian County, Shaanxi Province as a carrier (project no. 2021ND0167), and Xi'an Polytechnic University, research on taking the reform and practice of stop-motion animation curriculum (project no. 21JGYB28).

\section{References}

[1] M. J. Liu, F. R. Yang, and D. Bin, "A strategic study on the development of high school science curriculum resources based on digital sensor platform," Journal of Fujian Institute of Education, vol. 18, no. 2, pp. 95-97, 2017.

[2] L. Li and Y. Wang, "Teaching and exploring sensor technology based on artificial intelligence," Advances in Textile Science and Technology, vol. 1, no. 12, pp. 54-55, 2017.

[3] M. R. Jimenez-Liso, M. Martinez-Chico, L. Avraamidou, and R. López-Gay Lucio-Villegas, "Scientific practices in teacher education: the interplay of sense, sensors, and emotions," Research in Science \& Technological Education, vol. 39, no. 1, pp. 44-67, 2021.

[4] L. P. Tao, X. Tang, and W. H. Huang, "Design of information teaching based on "craftsman spirit" before, during and after class -- taking robot vision and sensing technology as an example," Mechanical management development, vol. 199, no. 11, pp. 264-266, 2019.

[5] H. B. Su and Y. L. Ma, "Application of digital technology in industrial electrical automation," Modern industrial economy and informationization, vol. 8, no. 162, pp. 43-44, 2019.

[6] P. Bettini, R. Torchio, F. Lucchini, D. Voltolina, and P. Alotto, "Fast Fourier transform-volume integral: a smart approach for the electromagnetic design of complex systems in large fusion devices," Plasma Physics and Controlled Fusion, vol. 63, no. 2, Article ID 025010, 2020.

[7] Z. Zheng, "Research progress and application prospect of intelligent sensor technology," Tech review, vol. 34, no. 17, pp. 72-78, 2016.

[8] K. Asibu, "Modeling of conduction mode laser welding process for feedback control," Journal of Manufacturing Science and Engineering, vol. 122, no. 3, pp. 420-328, 2016.

[9] X. D. Xu, "Application of sensor technology in mechatronics system," Technology outlook, vol. 26, no. 8, p. 78, 2016.

[10] X. A. Fan, X. Gao, G. Liu, N. Ma, and Y. Zhang, "Research and prospect of welding monitoring technology based on machine vision," The International Journal of Advanced Manufacturing Technology, vol. 115, no. 11, pp. 3365-3391, 2021. 
[11] W. Wang and $\mathrm{X}$. Wu, "Reform and practice of teaching a sensor technology course based on engineering concepts," International Journal of Continuing Engineering Education and Life Long Learning, vol. 28, no. 3-4, pp. 358-372, 2018.

[12] X. Yu, Y. F. Fang, and Y. L. Ge, "Exploration and research on the ideological and political teaching of sensor and detection technology course under the background of intelligent robot," Modernization of education, vol. 6, no. 99, pp. 48-49, 2019.

[13] G. Chen, H. Cao, J. Conradt, H. Tang, F. Rohrbein, and A. Knoll, "Event-based neuromorphic vision for autonomous driving: a paradigm shift for bio-inspired visual sensing and perception," IEEE Signal Processing Magazine, vol. 37, no. 4, pp. 34-49, 2020.

[14] D. Dziob, M. Krupiński, E. Woźniak, and R. Gabryszewski, "Interdisciplinary teaching using satellite images as a way to introduce remote sensing in secondary school," Remote Sensing, vol. 12, no. 18, p. 2868, 2020.

[15] L. Morra, S. P. Mohanty, and F. Lamberti, "Artificial intelligence in consumer electronics," IEEE Consumer Electronics Magazine, vol. 9, no. 3, pp. 46-47, 2020.

[16] D. Amo, P. Fox, D. Fonseca, and C. Poyatos, "Systematic review on which analytics and learning methodologies are applied in primary and secondary education in the learning of robotics sensors," Sensors, vol. 21, no. 1, p. 153, 2021.

[17] S. L. Chen, J. L. Huang, and W. W. Zeng, "Design of industrial automation sensor teaching experiment platform," Chemical automation and instrumentation, vol. 45, no. 8, pp. 640-643, 2018.

[18] A. L. Evans, A. J. Bulla, and A. R. Kieta, "The precision teaching system: a synthesized definition, concept Analysis, and process," Behavior Analysis in Practice, vol. 14, pp. 1-18, 2021.

[19] A. J. Bulla, A. Calkin, and M. Sawyer, "Introduction to the special section: precision teaching: discoveries and applications," Behavior Analysis in Practice, vol. 14, no. 3, pp. 555-558, 2021.

[20] Z. C. Liang, "Application and case study of ultrasonic motion sensor in teaching," Digital teaching in primary and secondary schools, vol. 30, no. 6, pp. 84-87, 2020.

[21] L. Liu, "Sensor application technology "information teaching practice -- taking the teaching design of understanding temperature sensor as an example," The digital world, vol. 175, no. 5 , p. $127,2020$.

[22] M. Chen, "Use a variety of teaching methods to improve the effectiveness of sensor teaching," Science \& Education, vol. 383, no. 4, pp. 100-101, 2017.

[23] J. Jovaisaite, D. Cirule, A. Jeminejs et al., "Proof of principle of a purine $\mathrm{D}-\mathrm{A}-\mathrm{D}^{\prime}$ ligand based ratiometric chemical sensor harnessing complexation induced intermolecular PET," Physical Chemistry Chemical Physics, vol. 22, no. 45, pp. 26502-26508, 2020.

[24] W. Wei Dan, R. Ren Xian, and M. Q. Ma Qi Hua, "Research on the construction of courses of automotive electronics and electrical appliances based on the joint training mode of vocational schools and applied undergraduate courses," Britain International of Humanities and Social Sciences (BIoHS) Journal, vol. 2, no. 1, pp. 1-8, 2020.

[25] K. Watanabe, Y. Kurihara, K. Kobayashi, and K. Suzuki, "Inbed biosignal acquisition from conventional differential pressure sensor based on thermal flow principle," IEEE Sensors Journal, vol. 21, no. 4, pp. 5340-5348, 2020.

[26] H. H. Hong and Y. Ye, "Ideological and political teaching reform of sensor and detection technology course," International public relations, vol. 97, no. 1, pp. 72-74, 2020.
[27] F. Yao and A. Zhang, "Integration of education management and mental health in psychological crisis intervention in colleges and universities," ASP Transactions on Psychology and Education, vol. 1, no. 1, pp. 31-38, 2021.

[28] L. P. Huang, "Exploration and research on the diversified teaching reform of test technology and sensor course," Science and Technology, vol. 32, no. 17, pp. 139-140, 2019.

[29] J. Tang, L. H. Li, and X. J. Huo, "Exploration on teaching reform of sensor courses in agricultural colleges," Farm staff, vol. 657 , no. 11 , p. 229, 2020.

[30] J. Peng, W. Feng, Z. Yue, and X. Yang, "Fiber-optic FabryPerot temperature sensor based on the ultraviolet curable glue-filled cavity and two-beam interference principle," Zeitschrift für Naturforschung A, vol. 76, no. 2, pp. 175-179, 2021.

[31] T. Liu, "Exploration of "student-centered" teaching method reform in sensor and detection technology course," Heilongjiang Science, vol. 10, no. 156, pp. 20-23, 2019.

[32] L. Liang, "Exploration and practice of network teaching of sensor and detection technology based on OBE concept," The wind of science and technology, vol. 422, no. 18, p. 71, 2020. 